\title{
La planificación del espacio urbano: El turismo, lo cultural y gastronómico. Luces y sombras a 100 años del barrio Güemes
}

\section{Sección ESTUDIOS}

RECIBIDO: 09/09/2021

APROBADO: 20/09/2020

PUBLICADO ONLINE: 30/12/2021

\author{
Ailen Suyai Pereyra ${ }^{1}$ \\ Universidad Nacional de Córdoba \\ ailen.suyai.pereyra@unc.edu.ar \\ https://orcid.org/0000-0003-1796-4271
}

\section{RESUMEN}

En los últimos veinte años determinados sectores de las ciudades asisten a una reconfiguración que reproduce el modo de producción capitalista actual. En este marco, la agenda estatal plantea una serie de celebraciones y conmemoraciones espectaculares que operan como lógicas de suturación ideológica en contextos socio-segregados. La ciudad de Córdoba no es la excepción a estos procesos y también a un conjunto de articulaciones de sujetos y prácticas intervienen en transformaciones que generan nuevas formas de experimentar y producir en áreas a partir de diversas lógicas. El trabajo plantea desde una perspectiva cualitativa, en un primer momento, un recorrido por los puntos de inflexión históricos y de la política urbana que actualizan la memoria, obturan espacios urbanos y continúan con formas de dominación en el escenario barrial. Se postula que el polo comercial es parte de la estrategia estatal y privada para caracterizar el festejo del centenario del barrio. Luego, se describe el programa "Güemes Centenario: 100 bares en Ocho Manzanas" como reconstrucción de la experiencia social que une lo turístico, cultural y gastronómico. Finalmente, se reflexiona sobre cómo se construye el discurso social en torno a los festejos de los 100 años del barrio Güemes.

PALABRAS CLAVE: planificación urbana, turismo, polo comercial, estrategia estatal y privada

1 Becaria Posdoctoral de CONICET, lugar de trabajo en el Instituto de Investigación de Vivienda y Hábitat (INVIHAB) Grupo Vinculado Instituto de Humanidades (IDH-CONICET-UNC). Miembro del "Programa de Ideología y Prácticas Sociales en conflicto"CIECS-CONICET. Docente del colegio Nacional Monserrat. Córdoba, Argentina.

(c) Los autores. Este artículo es publicado por la Revista de Sociología de la Facultad de Ciencias Sociales, Universidad Nacional Mayor de San Marcos. Este es un artículo de acceso abierto, distribuido bajo los términos de la licencia Creative Commons Atribución 4.0 Internacional (CC BY 4.0) [https://creativecommons.org/licenses/by/4.0/deed.es] que permite el uso, distribución y reproducción en cualquier medio, siempre que la obra original sea debidamente citada de su fuente original. 


\title{
Planning of urban space: tourism, culture and gastronomy. Lights and shadows 100 years from the Güemes neighborhood
}

\begin{abstract}
In the last twenty years, certain sectors of the cities have witnessed a reconfiguration that reproduces the current capitalist mode of production. In this framework, the state agenda proposes a series of spectacular celebrations and commemorations that operate as logics of ideological suturing in socio-segregated contexts. The city of Córdoba is not the exception to these processes and also a set of articulations of subjects and practices intervene in transformations that generate new ways of experimenting and producing in areas based on different logics. This work presents from a qualitative perspective, at first, a journey through historical turning points and urban politics that update memory, block urban spaces and continue with forms of domination in the neighborhood scene. It is postulated that the commercial pole is part of the state and private strategy to characterize the celebration of the centenary of the neighborhood. Then, the program "Güemes Centenario: 100 Bares en Ocho Manzanas" is described as a reconstruction of the social experience that blends the tourism, the culture and the gastronomy. Finally, it reflects on how the social discourse is built around the celebrations of the 100 years of the Güemes neighborhood.
\end{abstract}

KEYWORDS: Urban planning, tourism, commercial pole, state and private strategy.

\section{Introducción}

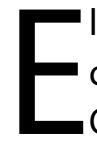

presente artículo se enmarca en el análisis de los discursos sociales en el contexto de los festejos de los 100 años del barrio Güemes de la ciudad de Córdoba². Se centra en el plan “Güemes Centenario: 100 Bares en Ocho Manzanas", implementado a partir de la Municipalidad de Córdoba, específicamente de la Dirección General de Turismo en conjunto con los bares del mencionado barrio. Se analizan los circuitos turísticos y gastronómicos emergentes como "Córdoba con Sabor" que se inauguraron por los festejos del barrio Güemes. En este marco, la agenda estatal plantea una serie de celebraciones y conmemoraciones especiales que operan como lógicas de suturación ideológica en contextos socio-segregados. Dichos eventos están orientados a fortalecer turísticamente a Córdoba y a posicionar a la gastronomía como el "octavo arte".

2 La ciudad fue fundada el 6 de julio de 1573 por Jerónimo Luis de Cabrera y la denominó ciudad de Córdoba de La Nueva Andalucía. Según el sitio web de la provincia de Córdoba: el hecho se concretó "a orillas del río Suquía, en un sitio llamado Quizquizacate por los lugareños ("Encuentro de los ríos" en idioma sanavirón). El nombre dado por Cabrera a la ciudad es un homenaje a su ciudad natal, la ciudad española de Córdoba en la comunidad de Andalucía. Cabrera buscaba dos objetivos. Uno de ellos era disponer de una salida a "La Mar del Nord", es decir al Océano Atlántico, ya que creyó que la Laguna de Mar Chiquita era una bahía de este océano; y también intentó fundar una ciudad a orillas del río Paraná. El segundo de los objetivos era la fabulosa Ciudad de Los Césares, por esto desobedeció las órdenes del virrey del Perú y fundó la ciudad de Córdoba al sur de la jurisdicción que se le asignara". https://www.cba.gov.ar/provincia/historia/ 
En ese sentido, a diferentes escalas espaciales se materializaron tendencias que demuestran cómo los espacios se van transformando acorde al modo de reproducción capitalista (Harvey, 2013). Múltiples autores se encargaron de analizar cómo se vincula el fenómeno del turismo, la cuestión cultural y la oferta referida al consumo en ciertos sectores urbanos: en los barrios de San Telmo, Barracas, La Boca, Palermo en Buenos Aires (Herzer, 2012; Kozak y Vecslir, 2013; Carman, 2011); el pueblo de Tequila en Jalisco México (Hernández, 2009); New Orleans, la calle 125th en los Estados Unidos (Gotham, 2004; Zukin, 2010), el distrito de Kreuzberg- Friedrichshain en Berlín (Novy, 2013), son solo algunos ejemplos de dicho fenómeno. La transformación de estas áreas obedece a la falta de rentabilidad y el discurso en torno a un espacio "obsoleto" (Carman, 2011; Harvey, 2013). También se ponen en juego, el rol que cumplían otrora, es decir las funciones económicas y sociales que albergaban y se constituyeron como escenario donde sucedieron hechos históricos. A la par, la omisión de acciones públicas y/o privadas, la desatención y el crecimiento de situaciones sociales conflictivas (delitos, inseguridad, degradación) en estos espacios, operan como argumento para que los gobiernos locales comiencen a planificar una intervención con el objetivo de modernizarlos.

Ahora bien, Córdoba no es la excepción a estos procesos por lo que en los últimos 10 años las políticas públicas prepararon el espacio urbano para el desembarco de inversores privados en la dinámica barrial. Estos actores se los puede identificar a través de los nuevos comercios, también con la llegada de franquicias, marcas de autor y reconocidas internacionalmente (Boito y Pereyra, 2016). Las iniciativas de la Municipalidad de Córdoba se las puede dividir en dos grandes tipos: por un lado, una modificación del corpus normativo con el objetivo de regularizar la edificación en altura o cambios en la densidad de construcción y habilitar cada vez más negocios en ciertos sectores (Pereyra, 2021b). Por otro lado, el impulso y la co-organización con grupos económicos de eventos que convocan visitantes o turistas, se muestra un lado maquillado de los hechos barriales. Estas manifestaciones exhiben al área de forma estática, a-conflictiva o en algunos casos se remontan a épocas coloniales o incluso previo a la formación actual del barrio (principios de XX). De esta manera, en el espacio urbano intervienen una articulación de sujetos y prácticas que generan nuevas formas de experimentar/producir en áreas a partir de diversas lógicas.

\section{Metodología}

El trabajo plantea desde una perspectiva cualitativa, tres momentos de análisis. En un primer momento, se realiza un recorrido y cruce entre los puntos de inflexión 
históricos y de la política urbana (en todos sus niveles) que actualizan la memoria, obturan espacios urbanos y continúan con formas de dominación en el escenario barrial. Se postula que el polo comercial es parte de la estrategia estatal y privada para caracterizar el festejo del centenario del barrio. Por lo que, se llevará a cabo un análisis de contenidos de los documentos sobre los hechos históricos-espaciales de trascendencia en el barrio Güemes. La mirada histórica de las transformaciones, habilitó la reconstrucción socio histórica barrial a partir de documentos y los planos, ordenanzas y catálogos municipales (Dirección de Catastro de la Municipalidad de Córdoba).

Luego, se realiza una descripción del programa "Güemes centenario: 100 bares en Ocho Manzanas" como reconstrucción de la experiencia social que une lo turístico, cultural y gastronómico. Finalmente, se identifican y seleccionan noticias informativas para reflexionar sobre cómo se construye el discurso social en torno a los festejos de los 100 años del barrio Güemes. Al respecto de esto se tuvieron en cuenta artículos periodísticos en los cuales emergieron celebraciones por el cumpleaños del barrio y lo relacionado con el mismo. Aunque este apartado no tiene por objetivo realizar un análisis profundo en lo semiótico, una caracterización de los marcos de interpretación que construyen los medios de comunicación masiva y gráfica permiten echar luz en cómo se configuran los mecanismos unificadores y reguladores que participan en la homogeneización de los discursos sobre este territorio. El espacio social y sus transformaciones son fuerzas constituyentes de las experiencias contemporáneas y de las relaciones sociales, posibles y deseables.

\section{Tendencias espaciales en sectores urbanos}

Una corriente de autores, coinciden que en la década de los setenta el neoliberalismo comienza a tener relevancia en los Estados nacionales debido a la baja rentabilidad de las industrias de producción masiva y a la crisis del Estado de Bienestar keynesiano (Theodore, Peck y Brenner, 2009). Dentro de estos procesos, las transformaciones urbanas en el neoliberalismo realmente existente (Theodore, Peck y Brenner, 2009) están sujetas a la lógica capitalista y en algunos casos son una consecuencia de las políticas de gestión empresarial (Harvey, 2013). En ese sentido, un rasgo a tener en cuenta en el neoliberalismo realmente existente son las"interacciones dependientes de la trayectoria y contextualmente específicas que se dan entre los escenarios regulatorios heredados (...) y proyectos emergentes de reformas neoliberales orientados al mercado" (Theodore, Pecky Brenner, 2009, p. 3). 
Siguiendo con la trayectoria de Robert Jessop (2008), el autor concibe al capitalismo como un modo de producción y asimismo como objeto de regulación de las interacciones de las relaciones sociales que se encuentran fuertemente intervenidas por el mercado. Por lo que, se avizora una nueva cristalización del Estado, el cual está destinado a promover las condiciones económicas y extraeconómicas necesarias para el régimen de acumulación posfordista. Los espacios urbanos contemporáneos asistieron a una reconfiguración, pues se los consideraba lugares estratégicos que dieron lugar al avance de proyectos reestructuradores neoliberales y por lo tanto se dispusieron para la inversión de capital y el incremento de la renta económica.

La crisis en el sector secundario, hizo virar las inversiones hacia el sector terciario y cuaternario. Esto significó que algunas zonas dentro de las ciudades, adquirieron relevancia debido a su ubicación estratégica o por el hecho de contar con servicios urbanos que las hacían atractivas para el emplazamiento de nuevos proyectos urbanos. De esta manera, se plantearon políticas urbanas con el objetivo de impulsar acciones de renovación o rehabilitación que dinamizarán económicamente determinados sectores (Marengo, 2010). Desde la noción de recuperación del patrimonio y la gestión cultural de los territorios, surgió el turismo como una herramienta económica para producir un excedente de plusvalía. La puesta en valor de bienes tangibles e intangibles atrajo la afluencia de visitantes $y$, a la vez, produjo una retroalimentación en los espacios.

En otras partes del mundo varios autores estudiaron estos procesos, algunos ejemplos de ello son: en los barrios de San Telmo, Barracas, La Boca, Palermo en Buenos Aires (Herzer, 2012; Kozak y Vecslir, 2013; Carman, 2011); el pueblo de Tequila en Jalisco México (Hernández, 2009); New Orleans, la calle 125th en los Estados Unidos (Gotham, 2004; Zukin, 2010), el distrito de Kreuzberg-Friedrichshain en Berlín (Novy, 2013). El rasgo común entre los mencionados casos fue la falta de rentabilidad y la degradación, que habilitaron la implementación de obras públicas. Sin embargo, la implementación de proyectos transformadores se redujo principalmente a elementos morfológicos, físicas y estéticos, dejando en un segundo plano el impacto en el espacio próximo y las interrelaciones entre los habitantes y otros actores con su territorio.

Ahora bien, a escala nacional paulatinamente desde fines de los setenta el rol del Estado fue virando de un Estado interventor del tipo keynesiano hacia uno del tipo competitivo en el marco del cambio del régimen de acumulación de capital. Argentina se insertó en una nueva división internacional-regional del trabajo privilegió los espacios cuyas economías fueran susceptibles de amoldarse a las demandas del mercado global (Marengo, 2010). Luego de la apertura democrática en 1983 y en 
los noventa se establecieron en la nación un paquete de medidas neoliberales, tales como: apertura externa, privatización, desregulación, flexibilización laboral, entre otras, que terminaron por romper la base del Estado benefactor. En otras escalas (provincia y municipio), esto se replicó en formas de planificación y ordenamiento territorial vinculado al surgimiento del modelo de ciudad competitivo. En el caso de la ciudad de Córdoba, se elaboraron planes estratégicos que buscaron modernizar a la ciudad e insertarla a un mundo globalizado.

Bajo estos indicios se propone tener como punto de partida cómo diversos gobiernos locales tienden a planificar el espacio y como se ponen en juego fechas conmemorativas que priorizan el valor de cambio. Desde una lógica mercantil se consolidan en el territorio círculos de encierro/entornos protegidos, nuevas formas de experimentar/producir en áreas a partir de diversas lógicas y como consecuencia consolidan una mayor fragmentación socio espacial.

\section{La planificación urbana en la ciudad de córdoba}

La noción de embellecimiento estratégico como categoría analítica permite reflexionar en torno a las transformaciones urbanas y sociales impuestas por reproducción constante del capital (Benjamin, 1999; Boito y Espoz, 2014). En este sentido, en la Ciudad de Córdoba hace más de 20 años se viene implementando una serie de políticas urbanas que operan como dispositivos de separación clasista. Específicamente, se generaron ordenanzas municipales referidas al impulso del turismo a través de la patrimonialización de lugares y mecanismos que segregan a sectores de clase baja. Como antes se afirmó, este fenómeno de escala local, Córdoba responde a un proceso global el cual se puede denominar urbanismo estratégico (Boito y Espoz, 2014). Dicho proceso requirió de dos fases, por un lado, la relocalización de población de clase baja hacia las afueras del ejido urbano en los "ciudad-barrio" junto con la planificación del trazado de algunas vías de circulación. A la par, sucedió en el centro histórico y comercial y en barrios pericentrales un fenómeno llamado renovación urbana (Pereyra, 2021a; Marengo, 2021). Los barrios pericentrales, también pueden ser denominados barrios tradicionales, los cuales son San Vicente y General Paz hacia el este, Alberdi hacia el oeste concomitante con la direccionalidad del valle, Güemes al suroeste, Alta Córdoba al norte cruzando el cauce Río Suquía, Nueva Córdoba al sur y Cerro de las Rosas al norte. Los mismos, son considerados así porque fueron localizados en sus comienzos fuera del centro fundacional de la ciudad, nacieron con cierta autonomía, sin embargo, con una fuerte dependencia 
funcional de su centralidad. La amojonada del conjunto urbano, el escaso desarrollo en términos urbanísticos y el hecho que tuvieran funciones sociales y económicas en la plaza barrial significó que funcionaron como una extensión suburbanas hasta fines del siglo XIX. En un principio los barrios se configuraron como la periferia moderna, ya que fueron los primeros en poseer servicios urbanos como tendido eléctrico, división de parcelas, tranvía, almacenes de ramos generales entre otros y eran heterogéneos respecto del Área Central (Marengo y Pereyra, 2022).

Retomando la propuesta de análisis, tanto las políticas orientadas al impulso turístico y a la patrimonialización fueron modificando las prácticas y experiencias de los pobladores que interactúan en la ciudad y con el espacio urbano en particular. Es decir, se reconfiguran las formas de socialización en torno al barrio y el todo urbano.

Esto fue posible gracias a la articulación normativa entre el binomio EstadoMercado. La Reforma del Estado del año 2000 permitió el ingreso de capital privado en la planificación estatal de la ciudad. La unión posibilitó transformaciones que consolidaron entornos fuertemente segregados por clases sociales y avances de desarrollos inmobiliarios en los ya mencionados barrios tradicionales. A su vez, se desarrollaron zonas que brindan servicios del tipo turísticos con el objetivo de potenciar la llegada de visitantes, extranjeros y de experimentar un paquete de experiencias en estos espacios. Siguiendo a Harvey (2013) la inversión en infraestructura, edificación y vías de circulación fueron los principales focos de transferencia de capital. En este marco, se identificó que con la incorporación de inmuebles como parte del Patrimonio de la Humanidad según la UNESCO (en los 2000) y el contexto del Bicentenario de la Patria se sentaron las bases de la revalorización de áreas patrimoniales que guardan un potencial histórico-cultural de Córdoba. Los bienes inmuebles seleccionados conforman la Manzana Jesuítica integrada por la Universidad Nacional de Córdoba, la Iglesia de la Compañía de Jesús, la residencia de los padres jesuitas, el colegio Nacional Monserrat, y las estancias jesuíticas (ubicadas en diferentes puntos de la provincia de Córdoba). Previamente, en los preparativos del Bicentenario en 2010 se presentó en 2008 el Plan Director y se sancionaron múltiples ordenanzas con el objetivo de recuperar y poner en valor puntos específicos, fachadas y edificios ${ }^{3}$. Así, se intervinieron sitios reconocidos y se los volvió lugares de entretenimiento, en lo que pueden acceder y consumir algunas clases sociales. En esa línea, el Estado provincial materializó festejos y normativas en obras conmemorativas que pusieron el acento en exhibir

3 Obras tales como: el Paseo Buen Pastor (ex cárcel de mujeres), el Paseo de las Artes (Plaza de las carretas creada en 1864 del sector denominado Pueblo Nuevo), el Parque las Tejas (ex casa de gobierno), Avenida Hipólito Yrigoyen, complejos de departamentos en Alberdi y General Paz, entre otros. 
una Córdoba para el turismo. De allí la construcción de terminales de ómnibus, paseos, museos y parques orientados a un público particular (Pereyra, 2021b). En suma, la presencia de nuevos actores económicos en el territorio y el revés de la alianza entre el Estado y Mercado provocaron una serie de transformaciones que implicaron aumento en el valor del suelo urbano, cambios en los usos y disposición, crecimiento de construcciones en altura y a la par desplazamientos poblacionales y un incipiente proceso de gentrificación.

No casualmente, el área de estudio fue seleccionada en reiteradas ocasiones para implementar planes/proyectos. Coincidentemente, se trata de uno de los sectores con mayores cambios y en el cual se generaron nuevas formas de habitar/experimentar/producir en el espacio barrial a partir de diversas lógicas. En el próximo apartado se profundizará en normativas del orden de lo patrimonial, lo cultural y lo turístico.

\section{Puntos de inflexión en la historia barrial de Güemes}

Dentro del imaginario cordobés al barrio Güemes se lo reconoce como parte de los barrios tradicionales, como antes se mencionó, estos fueron las primeras expansiones urbanas que carecieron de una planificación tanto estatal como privada (Boixadós, 2000). Se constituyeron como parte de la periferia moderna y heterogénea del Área Central, aunque con una fuerte dependencia de la misma. Si bien poseían varios servicios urbanos, la traza barrial se reducía a un par de manzanas. Antes de constituirse como barrio, estaba conformado y dividido por cuatro fracciones: La Bomba, el Infiernillo, Pueblo Nuevo y El Abrojal localizables en el territorio hasta principios del siglo XX (Pereyra y Quevedo, 2020). Actualmente está ubicado en el sudeste y a 200 metros del centro de la ciudad (Figura 1). Los barrios que rodean a Güemes ${ }^{4}$ son: al norte Alberdi y el centro, al oeste Nueva Córdoba y un sector de Ciudad Universitaria, hacia el este Bella Vista y Observatorio y hacia el sur colinda con barrio Cáceres y Colinas de Vélez Sarsfield. Con el fin de reconstruir la historia del barrio, se realizará un repaso de los puntos de inflexión en él.

4 Los límites catastrales están comprendido por las calles de Boulevard San Juan hasta Miguel del Corro, siguiendo por esta hasta la Avenida Julio Argentino Roca tomando el Hospital Misericordia, el Instituto Antirrábico y la ex cárcel de Encausados. Hacia el oeste su límite es la calle Vélez Sarsfield.

Según el censo nacional de personas de 1991 había: 13.375 habitantes; en el 2001: 11.679 habitantes; en el 2008 el censo provincial registró 11.479 habitantes. La contabilización fue 2010 con 11.000 habitantes (Pereyra, 2021a). 
A fines de la década de 1880, el intendente Luis Revol destinó un espacio que había funcionado como lugar de carga y descarga de provisiones (Plaza de las Carretas) para el "Plan de viviendas obreras". La crisis económica y social y la fuerte oposición de la época fueron factores que obstaculizaron la finalización de dicho plan, por lo que este espacio quedó en estado de abandono y en ocasiones sirvió como refugio para personas en situación de calle o como albergue durante las crecidas del arroyo de La Cañada. Recién cien años después, se inaugura el "Paseo de las Artes" como un área designada para la artesanía en Córdoba. En principios, la feria ocupaba la Plaza Seca donde alrededor de 60 artesanos exponían sus trabajos los fines de semana y feriados. En la actualidad ocupan la plaza y las calles de alrededor aproximadamente más de 600 artesanos. Según la Municipalidad de Córdoba, concurren los fines de semana de 7.000 a 10.000 personas, entre turistas, habitantes del barrio y otros visitantes.

El barrio Güemes, específicamente el sector colindante al centro, otrora denominado "Pueblo Nuevo", sistemáticamente fue foco de planes/proyectos de modernización. Coincidentemente Pueblo Nuevo, es el territorio de mayor transformación en relación al valor del suelo, sus usos y disposición y la emergencia de nuevos actores económicos. Brevemente se presentarán algunos de estos planes. Hacia los noventa, barrio Güemes fue incluido en el proyecto "Área de Planificación Concertada Parque Juan Kronfuss"s con el objetivo de: "la revitalización, revalorización y desarrollo sustentable de un sector del tradicional Barrio Güemes". En ese sentido, desde los inicios fue considerada una zona deteriorada en relación a Nueva Córdoba y el Centro. Con el antecedente histórico-espacial de la presencia de la feria de artesanos (Paseo de las Artes o Paseo de las Pulgas) y de algunas casas del Plan de Revol dedicadas a las bellas artes, surge la importancia de mantener el tejido social, el valor histórico y patrimonial. Según el Municipio, el área fue elegida para ser "desarrollada" por su "identidad propia, ya sea por su historia como por su dinámica de actividades comunes y diferenciadas del resto de la ciudad" (PECba, 2005, p. 122).

5 La elección del nombre alude al autor del proyecto del Hospital Misericordia y su alrededor, también al Centro de Rehabilitación y Orientación de Menores (Crom) y con el Instituto Antirrábico. La obra incluyó la representación gráfica mediante una planimetría de la Plaza del Paseo de las Artes, para lo cual se estipulaba extraer piso, nivelar y reconstruir el pavimento en los sectores afectados por las raíces de árboles, rehacer adoquines y pavimento, y el destape y reparación: de caños y del desagüe pluvial. Además, se repararon baños y se pintó el interior y frente del Paseo y el Museo Iberoamericano, sediado en la misma manzana. 


\section{Figura 1}

\section{El barrio Güemes en relación a la ciudad de Córdoba}

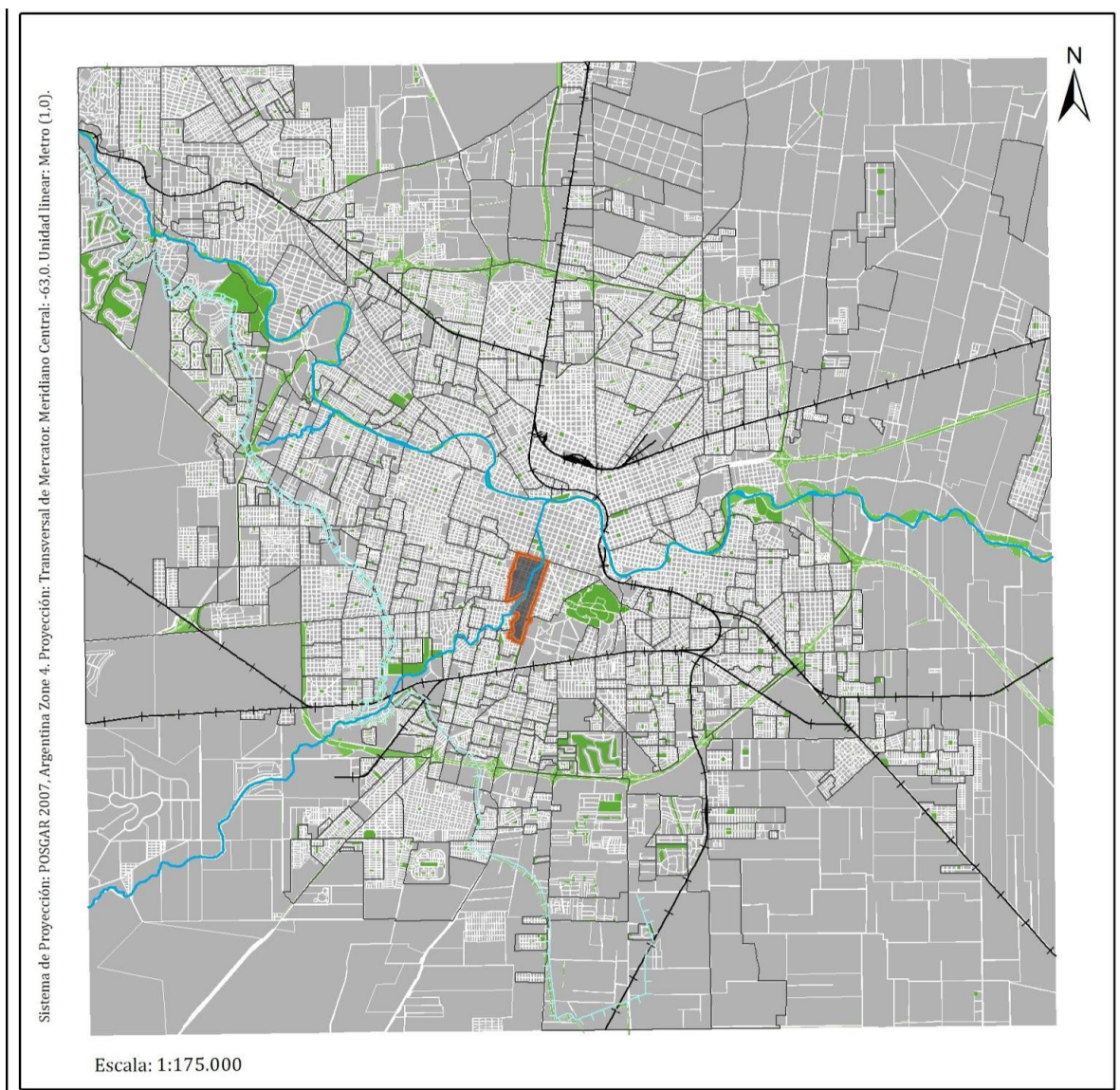

\section{Referencias}

Barrio Güemes

Barrios de la ciudad

Líneas Férreas

Canal

Cursos de Agua

Fuente de información cartográfica:

Dirección de catastro y Dirección Espacios verdes.

EspacioVerde

Manzana

Departamentos

Elaboración del producto cartográfico:

| Diseño cartográfico referencial

Lic. Ailen Suyai Pereyra. y Lic. Capdevila, M. Gabriela. Octubre 2019. 
La ubicación estratégica, su constitución como una primigenia expansión urbana de la ciudad a fines del siglo XIX y albergar atributos simbólicos, jugaron como factores para recuperar los bienes inmuebles patrimoniales. En esa línea, hacia el 2001 se sancionó la Ordenanza 10.402 de "Señalización de Bienes Patrimoniales", que consolidó la asociación patrimonial y la consideración de interés turístico de la zona colindante a Nueva Córdoba. Además, se implementó el "Programa de Recuperación de la Memoria Afectiva" (2003-2005) y en conjunto con un grupo de vecinos se construyó el "Libro callejero de Pueblo Nuevo y el Abrojal"6. Más tarde, la Ordenanza 11.202 (2007) postuló una serie de acciones de protección a los bienes considerados componentes del patrimonio (público o privados), incluidos en el Catálogo de "Bienes Inmuebles y Lugares del Patrimonio de la Ciudad de Córdoba". Preliminarmente se reglamentó la preservación de bienes patrimoniales y se creó un consejo asesor y un fondo de patrimonio. Sin quedarse atrás, el gobierno provincial (con la Ley 7232 en 2007) fomentó la promoción y desarrollo turístico para acompañar las acciones locales. Por lo que se estableció un área de investigación, desarrollo y asesoramiento, en consonancia con las actuaciones municipales y con el objetivo de administrar la Dirección de Turismo.

Más tarde en 2013, la actualización del catálogo de“Bienes Inmuebles y Lugares de Patrimonio de la Ciudad de Córdoba" (Ordenanza 12.201) permitió la incorporación de la leyenda "La Pelada de La Cañada" al Patrimonio Cultural Intangible e Inmaterial de la Ciudad (Ordenanza 12.241). Esta leyenda hace alusión al fantasma de una mujer que caminaba sobre los alrededores del arroyo La Cañada, se aparecía por la noche y perseguía a los que caminaban por allí.

En esta recopilación de ordenanzas municipales e instrumentos legales dejan en evidencia que la planificación barrial estaba atravesada fuertemente por la cuestión patrimonial y turística. Paulatinamente y en los últimos 15 años, se intensificó una zona del barrio como escenario de planes y proyectos, tal es el caso del plan "Portal Güemes" (2009) ${ }^{8}$ que buscó convertir la sección de Pueblo Nuevo en "corredor

6 El proyecto inicial buscaba colocar sesenta carteles en veredas y espacios públicos en las que habían sucedido acontecimientos barriales trascendentales.

7 El distrito 4: Güemes- Observatorio- Paso de Los Andes. En total 138 bienes divididos en categorías: inmuebles (130 bienes) y calles plazas, parques, puentes (8 bienes de categoría media). De los bienes inmuebles, 33 pertenecen a la categoría alta, 50 a la categoría media, 47 a la categoría baja y ninguno perteneciente a la categoría monumental.

8 En conjunto con la provincia y la Cámara de Turismo. Durante la intendencia Daniel Giacomino. La implementación de las obras comenzó en 2011 sólo se avanzó con la peatonalización del Pasaje Agustín Garzón, la colocación de cestos de basura y nuevo solado o vereda. 
cultural similar al de San Telmo (en Buenos Aires) para contemplar negocios de artesanías, antigüedades y galerías de arte"9 (La Voz del Interior, 2008).

En los dos periodos de Ramón Mestre ${ }^{10}$ (hijo) como intendente se llevaron a cabo dos planes de metas. El primero contempló dos ejes: Gestión del Estado local y Servicios al vecino y Plan de Desarrollo de la Ciudad. El segundo determinó cuatro lineamientos estratégicos: Córdoba Sustentable, Córdoba Competitiva, Córdoba Equitativa e Inclusiva y Desarrollo Institucional. Dentro de la línea "Córdoba Sustentable" se continuó con la visión de ordenamiento territorial, la movilidad urbana, la gestión ambiental y lo patrimonial, esto demuestra una fuerte intención de configurar un espacio con acceso restringido poblacional (Pereyra, 2021).

Lo anterior demuestra que los parámetros de lo deseable/indeseable y posible/ imposible en torno al turismo y patrimonio se consolidaron y mimetizaron como parte de la política pública. En este marco, reaparecieron ciertas categorizaciones espaciales: "obsoleto", "abandonado", en "desuso" operan como un argumento suficiente para intervenir el territorio y permitir por ejemplo la reconversión de estacionamientos de autos y viejas gomerías en galerías comerciales "sustentables"11 (2013). A su vez, esta imagen reciclada posicionó al sector popularmente, siendo uno de los más visitados por su impronta característica de innovación, bohemia, lo hippie y chic $^{12}$. Desde los discursos oficiales, los funcionarios públicos y el diario de mayor tirada en Córdoba "La Voz del Interior" lo definieron como un espacio de disfrute y de paseo para el turista. Un elemento sintomático que emergió fueron los comercios que comenzaron a instalarse en estas manzanas, se habilitaron 485 negocios entre los años 2013 y 2019, siendo el rubro de consumo de alimentos el que más creció.

Nuevamente, en la vorágine transformadora, la Municipalidad propuso eventos en conjunto con los bares y/o restaurantes que convocaban a los habitantes de Córdoba a visitar el barrio, en calidad de turistas. Ejemplo de ello fueron, los "Circuitos del Arte" (bimensuales) que comenzaron en 2015 con un tópico transversal y al cual se acoplaban todos los actores participantes. El circuito propiamente dicho, realizaba un breve recorrido por las instituciones estatales alojadas en el barrio y al finalizar se entrega una chequera de descuentos para consumir en la vecindad.

9 "Un plan para cambiarle la cara al Centro" (La Voz del Interior, 31/08/2008).

10 Pertenece al partido político de la Unión Cívica Radical.

11 La noción de sustentable aquí tiene que ver con la forma de construcción y los tipos de materiales que se utilizan en las edificaciones.

12 El texto hace referencia a la terminología del idioma inglés ya que surgieron de la pragmática de los usos sociales, es decir aparecen en los sentidos del barrio. La letra cursiva sigue los lineamientos de las normas APA 7ma edición.

Estos dos términos hacen referencia al estilo artesanal, rústico y bohemio del barrio. 
Dentro de la ráfaga de cambios, en las calles Montevideo, Pueyrredón y Marcelo Torcuato de Alvear la construcción en altura floreció rápidamente. Por lo que el Estado Municipal debió regularizar las construcciones con la actualización normativa que regulan el uso, la ocupación y el fraccionamiento del suelo en la ciudad y de alguna manera, allanaron el escenario barrial para el crecimiento inmobiliario ${ }^{13}$.

La modernización, la recuperación de áreas patrimoniales y la promoción del turismo se instalaron como parte del proceso de renovación urbana gestionado por alianzas público-privadas. Todo el escenario barrial se predispuso hacia una re-configuración del tejido edilicio, de los usos del suelo y de las actividades socioeconómicas presentes en el espacio. Los capitales privados invirtieron en unidades de vivienda de pequeñas dimensiones, en oferta comercial variada y creativa que apuntan hacia un público con altos ingresos y a personas externas al barrio y consumen del "renovado espacio".

\section{Gastronomía, cultura y turismo en el barrio Güemes}

Aunque el barrio Güemes se lo podía caracterizar por la presencia de la feria de artesanías, un lugar distintivo del tango y de expresiones artísticas con ciertos tintes vanguardistas, desde el 2000 en adelante este territorio presenta un límite difuso entre pares opuestos y complementarios: lo artesanal/moderno y lo autóctono/ trendy ${ }^{14}$.

En ocho manzanas se puede realizar un recorrido hippie-chic completo: visitar los puestos de artesanos dispuestos en la plaza histórica que conectan las calles aledañas (peatonalizadas durante los fines de semana) con variados productos $y$ rubros; luego por la calle principal, Belgrano, uno al lado del otro se puede consumir en bares, restaurantes, casas de té, entre otros. También, las galerías comerciales funcionan como corredores de paseos completos: negocios de variados artículos y la oferta de cervecerías, cafés y bares. Los visitantes disfrutan de la experiencia de vivir una acotada parte del barrio Güemes. El trayecto comienza por la tarde caminando por la feria, observando algún espectáculo callejero, tomando fotografías y la excursión finaliza entre luces tenues, música de elevado volúmen, cartas gourmets y una decoración que mezcla lo minimalista y lo bohemio.

13 También se reglamentaron las Áreas de Promoción Urbana (Arroyo La Cañada), el mantenimiento vial de la calle Marcelo T. de Alvear (2015) y en un sector del barrio se incorporaron farolas simulando un tipo de luminarias antiguas pero con tecnología LED.

14 Se denomina asía aquello que está de moda, en este caso una parte del barrio es reconocida por la ciudadanía cordobesa. 
Sin cesar, este sector conocido como Pueblo Nuevo con una impronta rústica, caótica y con recovecos se convirtió en un lugar de moda. Como se mencionó anteriormente, la constante apertura y recambio comercial se constituyeron como parte de la dinámica barrial. En principios arribaron franquicias o locales comerciales $^{15}$, que nada tenían que ver con la 'identidad artesanal/tanguera' de décadas pasadas. Por ejemplo, el caso paradigmático de "Estación Güemes" se erigió como "el" restaurante para ir a degustar comidas típicas, luego reconvertido en un lugar para los shows de comediantes, magos, cantantes, standuperos ${ }^{16}$, etc. Hasta el 2018, todas las semanas a modo de cartelera teatral, se exhibían en él nuevas propuestas atractivas para el turismo y el disfrute nocturno. Finalmente, luego de su cierre y un tiempo sin actividad se inauguró Club Paraguay, antes ubicado en la cercanía del Río Suquía. Actualmente, funciona como local nocturno bailable y lugar de emprendedores jóvenes cordobeses. Algo similar ocurrió con "El Arrabal", este local se emplazó en la esquina de Belgrano y Fructuoso Rivera y comenzó su actividad en 1999, era reconocido porque la oferta giraba en torno al tango. Hacia el 2016 cerró por falta de público interesado en concurrir, en tal solo dos meses se lo sustituyó por "Oye Chico" una franquicia caracterizada por la temática cubana y/o caribeña. Durante su funcionamiento, desató más de una polémica debido al alto volumen de la música, la masiva concurrencia y los espectáculos que brindaba. A posteriori, con la pandemia del covid-19 el club cerró y cambió de rubro comercial, desde fines del 2020 se encuentra allí una mueblería.

Ahora bien, estas transformaciones comerciales están fuertemente vinculadas con la propuesta que desde la Municipalidad de Córdoba se busca extender en el sector colindante con el barrio de Nueva Córdoba. En el marco del cumpleaños del barrio Güemes, se desarrolló el proyecto "Güemes Centenario: 100 bares en Ocho Manzanas", este operó como puente que reconstruye la experiencia social entre lo turístico, lo cultural y lo gastronómico. Las celebraciones por los 100 años del barrio fueron organizadas por las Direcciones de Turismo y Promoción de la ciudad de Córdoba que dependen de la Secretaría de Gobierno (figura 2). La propuesta se llevó a cabo del 15 al 19 de septiembre de 2021 y:

"forma parte de una política turística consensuada con integrantes del sector privado en la coyuntura pandémica, la cual busca potenciar a la gastronomía

15 Algunas franquicias como Venezia (panadería-heladería), Havanna (alfajores), Oye Chico (local destinado para ritmos caribeños y shows), entre otros. Los espacios "fueron cambiando las ofertas, volviéndose más homogéneas; se abrieron tiendas de diseño, negocios de venta de ropa de marca y crecieron los locales gastronómicos "gourmet"'"' (Boito y Pereyra, 2016:14).

16 Este término refiere a monólogos de comediantes. 
cordobesa en todas sus expresiones, como estrategia de desarrollo de una amplia cadena de valor del destino". (sitio web "Voy de Viaje", 2021)

Figura 2

Presentación de "Güemes Centenario: 100 barres en Ocho Manzanas

\section{$\leftarrow$ Tweet}

Pablo R Bianco

@PRBianco

\section{Presentación de "Güemes Centenario: 100 bares en 8 manzanas"}

\section{Un nuevo producto para promocionar e impulsar a uno de los polos turísticos y gastronómicos más relevantes de la ciudad.}

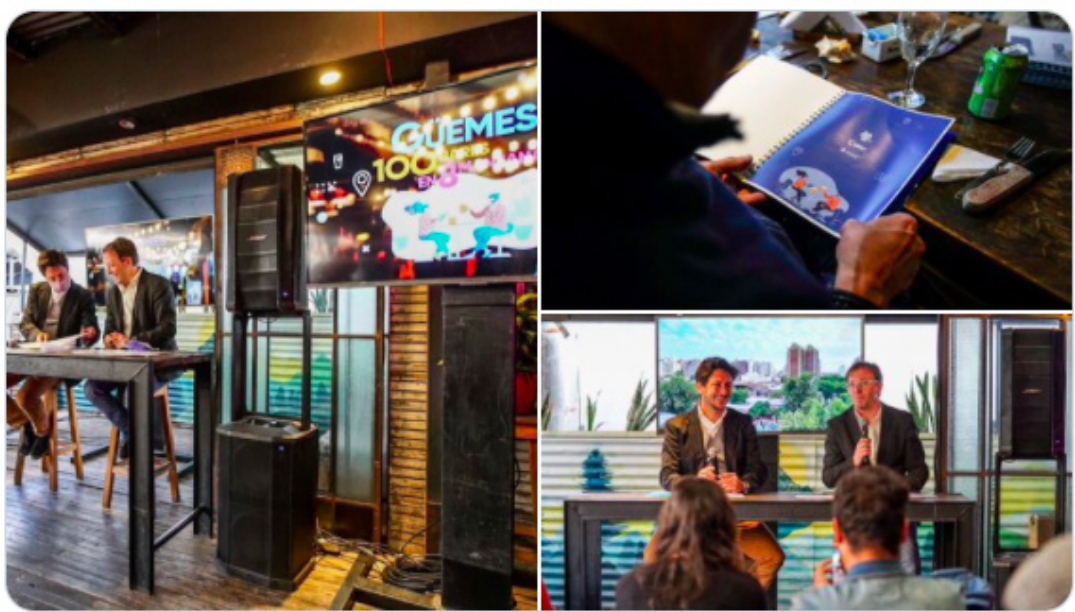

8 Pancho Marchiaro y 3 más

Nota: Pablo Bianco es Director General de Turismo, de la Municipalidad de Córdoba. Tomado de https://twitter.com/pmarchiaro/status/1401280520726659084

Este relato obtura cualquier probabilidad de conflicto entre el sector privado, los pobladores y la administración local. A la par, que homogeniza a toda la "gastronomía cordobesa" e invisibiliza la posición de los habitantes en el proyecto. Además, que plantea una potencial solución a contados inversores. El discurso expone el 
cambio de forma positiva de "la vieja denominación de Pueblo Nuevo y pasó a llamarse como lo conocemos"y este cambio permitió el desarrollo de "la actividad de ocio y esparcimiento crece vertiginosamente desde hace más de una década" (sitio web "Voy de Viaje", 2021). Asimismo, el barrio fue incluido en el circuito "Córdoba con sabor" (edición "Las horas más felices son") que incorporó "actividades en determinadas horas del día y en los diferentes polos gastronómicos de la ciudad, como Güemes, Zona Norte, Mercado Norte, General Paz y Barrio Jardín" (Turismo de la Municipalidad de Córdoba, 17/9/2021). En algunas de esas actividades se podía escuchar música en vivo con bandas y diferentes artistas en escenarios fijos y móviles que recorrieron las calles de la ciudad (figura 3). No es casualidad que en las áreas mejor cotizadas (en cuanto al valor del suelo urbano y actividad económica) de la ciudad se llevarán a cabo este tipo de eventos. Particularmente, el caso del barrio Güemes es considerado un barrio tradicional y de valor patrimonial, esto habilitó una retroalimentación económica y devino en un espacio para el paseo, el disfrute y orientado al consumo de grupos sociales con capacidad económica. Como explica García, "las maneras en que se transmite el saber de cada sociedad a través de las escuelas y los museos, demuestran que diversos grupos se apropian en formas diferentes y desiguales de la herencia cultural" (1999, p. 17). La participación social en el proceso de patrimonialización recibe apropiaciones selectivas y usos políticos según el contexto. El Estado se apropia de hechos históricos y los puede utilizar para (in)visibilizar momentos de acuerdo a su conveniencia.

\section{Figura 3}

Córdoba con Sabor

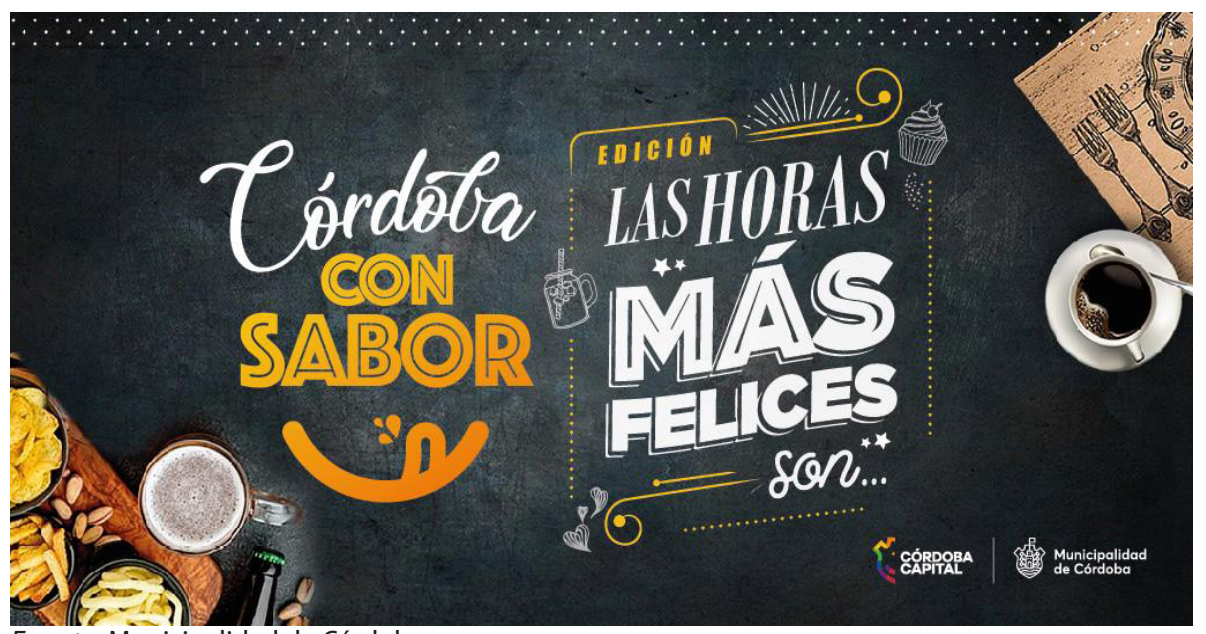

Fuente: Municipalidad de Córdoba. 
Este espacio reconvertido en pos de perpetuar la lógica mercantil propia del capitalismo, permite la conformación de percepciones, sensibilidades y el acondicionamiento de una identidad individual pero reconocida colectivamente $y$, a su vez, la modificación de las prácticas y experiencias de los pobladores. La noción de embellecimiento estratégico (Benjamin, 1999; Boito y Espoz, 2014) permite comprender que a través de la articulación pública-privada ${ }^{17}$ ciertas áreas son seleccionadas para implementar proyectos de renovación urbana (Boito y Pereyra, 2016; Pereyra, 2021a). Güemes es, ante todo, un enclave para el disfrute.

\section{"Cien años, cien bares y miles de historias"}

Retomando el inicio de este artículo, las principales urbes latinoamericanas y otros espacios urbanos del mundo se caracterizan por el crecimiento de la conflictividad. Esta se expresa en un aumento de la segregación social, discontinuidad en la trama, fractura del tejido social y fragmentación socio espacial. En un marco de la mediatización de los problemas urbanos se instalan como tópico de análisis en los mass media y construyen imágenes legítimas del mundo. Es por ello que, los medios de comunicación masiva juegan un papel central en la mediatización de la experiencia social en estos lugares cada vez más complejos (Espoz y Boito, 2017).

La ciudad de Córdoba y específicamente el barrio Güemes asiste a ciertas prácticas de consumo y de turismo, en un sector determinado. Por otro lado, y en otro sector, su cara opuesta se materializa en imágenes del deterioro e inseguridad construida como lo indeseable del barrio. Es decir, en él se encuentran "dos lógicas fundamentales para comprender las posibles y deseables (y sus anversos) experiencias de y en la ciudad actual" (Espoz y Boito 2017:51). Las diferentes transformaciones, tales como la edificación en altura, el arribo de franquicias, el cambio de un uso de suelo residencial por uno comercial, nuevo mobiliario urbano, la renovación de fachadas e incluso la llegada de más artesanos y apertura de espacios autodenominados independientes no pueden entenderse sino a la luz de procesos estructurales, legitimados por un determinado discurso social.

En las crónicas seleccionadas, los artículos periodísticos se centralizan en los festejos del centenario del barrio. Con la forma discursiva que se presentan se ob-

17 Las autoras afirman que "en este marco, emerge una nueva vinculación entre estética y política a partir de la regulación urbanística de la sensibilidad social desde donde se interpela a los cuerpos al interior de una ciudad fragmentada y clasista en nombre de propuestas progresistas o modernistas" (Almada, Quevedo y Pereyra, 2016:333). 
turan los conflictos del pasado y los actuales, las opiniones de los pobladores y las experiencias/vivencias de aquellos que lo transitan. El espacio se reduce sin más al paso de una nominación a otra. El resto del barrio aparece mencionado en términos románticos, a grandes rasgos, el tinte artesanal, 'arrabalero' y eventualmente se realiza una historización, o también emerge como la'fortuna' de la llegada de inversores trajo desarrollo económico. En palabras de Carman (2011) "algunos espacios se consagran en detrimento de otros, en los cuales lo diverso que se excluye está asociado, invariablemente, a formas de desigualdad" (p. 273). Así, desde el discurso informativo, se advierte cómo algunos topos adquieren importancia en la descripción del barrio Güemes y funcionan como si tuviesen una lógica autónoma y forman parte del discurso de algunos funcionarios públicos. Tal fue el caso de Francisco Marchiaro, Director de Promoción de la Ciudad, destacó que "ya no se tratará de un programa con algunas recetas, algunos platos específicos, sino con una franja horaria y un conjunto de ofertas y promociones que definirá cada establecimiento" (sitio web "Voy de Viaje", 2021). Esto posiciona a los dueños de locales comerciales con el poder de decisión sobre la carta de comidas y bebidas y los precios según lo que consideren. A su vez, se elogia la posición de los comerciantes, en palabras textuales de Bianco y Marchiaro"es significativo que no sea solo una iniciativa estatal sino del trabajo mancomunado de todas las partes, donde el municipio ha llegado para "empujar" el fenómeno que lleva más de una década" (sitio web "Voy de Viaje", 2021). Por otra parte, los funcionarios invitaron a escuchar una serie de podcast en Spotify $^{18}$ en las que se relatan la historia y anécdotas del barrio.

El festejo opera discursivamente como un instrumento que ordena lo deseable e indeseable del barrio. Aquí cabe una serie de preguntas: ¿cuál es el objetivo de celebrar los 100 años del barrio Güemes? ¿Quiénes son los invitados e invitadas a ese festejo? y ¿a quiénes está dirigido el cumpleaños del barrio? Cómo reza el slogan: "Las horas más felices son" entre las 18 y 20 horas para visitantes que pueden pagar los elevados costos, es decir son felices para pocos.

\section{Conclusiones}

Los 100 años del barrio Güemes de la ciudad de Córdoba, adquiere un sentido hegemónico y estructurado en torno a lo mercantil. Los festejos realizados durante

18 Este término alude a una serie de audios o archivos que los usuarios pueden escuchar y/o bajar a través de la aplicación de celular denominada Spotify. Esta aplicación fue fundada en 2006 y es de origen sueco. Los usuarios al descargarla en diferentes dispositivos pueden encontrar música o podcast de su interés. 
el mes de septiembre convergen en tres elementos: la patrimonialización, el turismo y lo comercial (gastronómico) que caracterizan la imagen actual del barrio. La coyuntura conmemorativa se apropia de hechos históricos y los convierte en una política orientada a impulsar el turismo y/o desarrollo económico. El valor de la dinamización tiene un lugar predominante en los discursos de funcionarios y por lo tanto en la planificación del espacio.

Este recortado barrio Güemes se convirtió en un entorno embellecido para ciertas clases sociales. Los circuitos promovidos por la Municipalidad, se concentra aquello digno de ser mostrados al visitante se expone la experiencia del disfrute, constituyendo recorridos cerrados en espacios abiertos. La posibilidad del paseo opera simbólicamente en las experiencias posibles, si las condiciones materiales lo permiten.

La figura del consumidor rige en la percepción contemporánea que actúa como aglutinador de múltiples experiencias (que se materializan en formas de atribución de prácticas, procesos, características, estilos de vida, etc.). Finalmente, como se auguraba, en los artículos informativos se menciona poco sobre los orígenes y conformación del barrio, sus residentes y trabajadores. El epicentro de las crónicas se limita a por donde ir a comer, beber, comprar y realizar actividades de entretenimiento.

El broche de oro es una imagen de un barrio embellecido que gira en torno un relato celebratorio en consonancia con lo patrimonial y una clara intención de la alianza público-privada de promocionar el desarrollo turístico dirigido hacia un sector poblacional.

\section{Bibliografía}

Angenot, M. (2010). El discurso social: los límites históricos de lo pensable y lo decible. Buenos Aires: Siglo XXI editores.

Ansaldi, W. (1997). Una Modernización Provinciana: Córdoba, 1880-1914. ESTUDIOS, 7, 8: 5180, Centro de Estudios Avanzados de la Universidad Nacional de Córdoba. https:// revistas.unc.edu.ar/index.php/restudios/article/view/13950

Arreortua, L. (2019). Transformaciones urbanas, procesos de gentrificación en ciudades latinoamericanas. En Marengo, C. et al. Crecimiento urbano: hacia una transformación sustentable del territorio (pp. 45-57), compilado por María Cecilia Marengo. Editorial de la FAUD-UNC, Córdoba, Argentina. 
Bischoff, E. (1997). Historia de los Barrios de Córdoba. Sus leyendas, instituciones y gente. Tomo I [1986]. Córdoba: Editorial Copiar.

Benjamin, W. (1999). París, capital del siglo XIX. En Benjamin, W., Poesía y capitalismo, Iluminaciones II, (pp.171-189). Madrid:Taurus.

Boito, E. y Espoz, M. (2014) (compiladoras). Urbanismo estratégico y separación clasista. Instantáneas de la ciudad en conflicto. Rosario: Puño y Letra Editorialismo de Base.

Boito, E. y Pereyra, A. (2016). Embellecimiento estratégico en la ciudad de Córdoba: continuidades, tensiones y rupturas en las prácticas del habitar en el barrio Güemes (2000-2014). Estudios Socioterritoriales, Revista de Geografía, 19, 13-29, Tandil.

Boixadós, M. (2000). Las Tramas de una ciudad, Córdoba entre 1870 y 1895. Élite urbanizadora, Infraestructura, poblamiento. Córdoba: Ferreyra editor.

Carman, M. (2011). El proceso de ennoblecimiento y la salida negociada de los innobles en Buenos Aires. Cadernos Metrópole, 13(25), 257-278, São Paulo. https://www. redalyc.org/articulo.oa?id $=402837820011$

Espoz, B. y Boito, E. (2017). Formas discursivas contemporáneas de juventud y sus límites: la construcción mediática de jóvenes de las clases subalternas en Córdoba, Argentina (2014). Cronos: Revista da Pós-Grad. em Ciências Sociais, UFRN, 18(1), 47-67. https:// periodicos.ufrn.br/cronos/article/view/13956/pdf

García, N. (1999). Los usos sociales del Patrimonio Cultural. Aguilar Criado, Encarnación (coord.), Patrimonio Etnológico. Nuevas perspectivas de estudio. Consejería de Cultura, España.

Harvey, D. (2013). Ciudades Rebeldes del Derecho de la ciudad a la revolución urbana. Salamanca: Akal.

Herzer, H. (2012) (comp.). Barrios al Sur. Renovación y Pobreza en la Ciudad de Buenos Aires. Buenos Aires: Editorial Café de las Ciudades.

Jessop, R. (2008). El futuro del Estado capitalista. Madrid: Catarata.

Kozak, D. y Vecslir, L. (2013). Transformaciones urbanas en la manzana tradicional. Desarrollos fragmentarios y micro transformaciones en el tejido del barrio de Palermo, Buenos Aires, en Cuaderno Urbano, 14, 147-171, Universidad Nacional del Nordeste, Buenos Aires. https://www.redalyc.org/articulo.oa?id=369233934007

Marengo, C. (2010). La planificación del crecimiento urbano: entre la regulación, la flexibilización normativa y las desigualdades socio-espaciales. Revista Científica Guillermo de Ockham, 8, 2, 69-83, Cali: Universidad de San Buenaventura Cali.

Marengo, C. [et al.] (2021). Transformaciones urbanas y políticas públicas: reflexiones para una agenda de investigación en hábitat. Editado por María Cecilia Marengo. - 1a ed compendiada. Córdoba: Editorial de la Facultad de Arquitectura, Urbanismo y Diseño de la Universidad Nacional de Córdoba. 
Marengo, C. y Pereyra, A. (2022). Habitar en contextos de renovación urbana: barrio Güemes, en Córdoba 2010-2015. Revista Arquitectura/Urbanismo/Sustentabilidad de la Universidad Austral de Chile. En prensa

Novy, J. (2013). Berlin Does not Love You: Notes on Berlin's Tourism Controversy and ist Discontents (pp. 223-237). In: BERNT, M., GRELL, B. \& HOLM, A., (eds), (2013). The Berlin Reader: a compendium on urban change and activism. Transcript Verlag.

Pereyra, A. (2021a). Continuidades, tensiones y rupturas en las prácticas del habitar en el marco de las transformaciones de barrio tradicionales. El caso barrio Güemes 2000-2016. [Tesis doctoral no publicada], Doctorado en Estudios Urbano Regionales de la Universidad Nacional de Córdoba y de la Bauhaus Universität Weimar.

Pereyra. A. (2021b). La (re)producción del capital y el impacto en el suelo urbano. El caso barrio Güemes, Córdoba (Argentina). Revista Direito da Cidade, 13, 3, 1357-1372, la Universidade do Estado do Rio de Janeiro. https://doi.org/10.12957/rdc.2021.61097

Pereyra, A. y Quevedo, C. (2020). La impugnación a la vivienda-rancho en la Ciudad de Córdoba (Argentina) entre los siglos XIX y XX. Revista Diálogos de la Universidad de Costa Rica, 21, 2, 247-269. https://revistas.ucr.ac.cr/index.php/dialogos/article/ view/41308

Quevedo, C., et. al (2016). El eterno retorno de lo "sustentable" Construcción discursiva y transformaciones urbanas de una Córdoba futurista. Chasqui, revista latinoamericana de comunicación, 131, 329-348, Quito.

Theodore, N.; Peck, J. y Brenner, N. (2009). Urbanismo neoliberal: la ciudad y EL IMPERIO de los mercados. Revista Temas Sociales n ${ }^{\circ} 66$. www.sitiosur.cl

Zukin, S. (2010). Naked City: the death and life of authentic urban places. Oxford, UK; New York: Oxford University Press

\section{Sitios Web consultados}

Voy de viaje. (2021). Güemes centenario: cien bares, cien años y mil historias en el barrio de Córdoba. https://www.voydeviaje.com.ar/cordoba/guemes-centenario-cienbares-cien-anos-y-mil-historias-en-barrio-de-cordoba

Turismo. (2021). Córdoba con sabor - edición "las horas más felices son..." https://turismo. cordoba.gob.ar/cordoba-con-sabor-edicion-las-horas-mas-felices-son-2021/

Circuito gastronómico. (2021). Córdoba con sabor: la municipalidad larga un ciclo de eventos especiales. https://www.circuitogastronomico.com/cordoba-con-sabor-la-municipalidad-larga-un-ciclo-de-eventos-especiales/ 
Calligaris, M. (2021). Hitos que marcaron a Güemes, un barrio cargado de historia. https:// www.cadena3.com/noticia/viva-la-radio/hitos-que-marcaron-a-guemesun-barrio-cargado-de-historia_304891

\section{Ordenanzas municipales y planes referenciados}

Plan Estratégico de la Ciudad de Córdoba. Una ciudad como su gente (PECba), Municipalidad de Córdoba (2003).

Portal Güemes 2009, Municipalidad de Córdoba

Plan de Metas 2012-2015, Municipalidad de Córdoba

Plan de Metas 2016-2019, Municipalidad de Córdoba

Ordenanza 8057, 1985. Ocupación del Suelo y Preservación de Ámbitos Históricos, Arquitectónicos y Paisajísticos dentro del Área Central de la Ciudad. Concejo Deliberante, Municipalidad de Córdoba.

Ordenanza 8256, 1986. Ocupación del Suelo. Concejo Deliberante, Municipalidad de Córdoba.

Ordenanza 11202, 2007. Establece acciones de tutela de valores culturales/paisajísticos de bienes componentes del Patrimonio. Concejo Deliberante, Municipalidad de Córdoba.

Ordenanza 12201, 2013. Reemplaza el Catálogo de Bienes Inmuebles y Lugares del Patrimonio Cordobés. Concejo Deliberante, Municipalidad de Córdoba.

Ordenanza 12.483, 2015. Uso y Ocupación del Suelo. Concejo Deliberante, Municipalidad de Córdoba. 